\title{
Effects of 60 minutes of hyperoxia followed by normoxia before coronary artery bypass grafting on the inflammatory response profile and myocardial injury
}

\author{
Inga Karu ${ }^{1,2^{*}}$, Peeter Tähepõld ${ }^{3,4}$, Arno Ruusalepp ${ }^{3,4}$, Kersti Zilmer $^{5}$, Mihkel Zilmer ${ }^{5}$ and Joel Starkopf $f^{2,4}$
}

\begin{abstract}
Background: Ischemic preconditioning induces tolerance against ischemia-reperfusion injury prior a sustained ischemic insult. In experimental studies, exposure to hyperoxia for a limited time before ischemia induces a low-grade systemic oxidative stress and evokes an (ischemic) preconditioning-like effect of the myocardium. We hypothesised that pre-treatment by hyperoxia favours enchanced myocardial protection described by decreased release of cTn T in the $1^{\text {st }}$ postoperative morning and reduces the release of inflammatory cytokines.

Methods: Forty patients with stable coronary artery disease underwent coronary artery bypass grafting with cardiopulmonary bypass. They were ventilated with 40 or $>96 \%$ oxygen for 60 minutes followed by by 33 (18-59) min normoxia before cardioplegia.

Results: In the $1^{\text {st }}$ postoperative morning concentrations of CTnT did not differ between groups ((0.44 (0.26-0.55) $\mathrm{ng} / \mathrm{mL}$ in control and $0.45(0.37-0.71) \mathrm{ng} / \mathrm{mL}$ in hyperoxia group). Sixty minutes after declamping the aorta, ratios of IL-10/IL-6 (0.73 in controls and 1.47 in hyperoxia, $p=0.03)$ and IL-10/TNF-a (2.91 and 8.81, resp., $p=0.015)$ were significantly drifted towards anti-inflammatory, whereas interleukins 6, 8and TNF-a and interferon- $\gamma$ showed marked postoperative rise, but no intergroup differences were found.

Conclusions: Pre-treatment by 60 minutes of hyperoxia did not reduce postoperative leak of $\mathrm{CTn} T$ in patients undergoing coronary artery bypass surgery. In the hyperoxia group higher release of anti-inflammatory IL-10 caused drifting of IL-10/IL-6 and IL-10/TNF-a towards anti-inflammatory.
\end{abstract}

Keywords: Coronary artery bypass grafting, Preconditioning, Hyperoxia, Troponin T, Cytokine, Interleukin, Tumor necrosis factor alfa, Interferon gamma

\section{Background}

Over 1 million coronary artery bypass grafting (CABG) operations are performed annually. In a large majority of patients the postoperative course is uneventful, i.e. without symptoms of major myocardial injury or systemic organ dysfunction. But in a small fraction of patients cardiac surgery results in a perioperative myocardial infarction, which is the major complication associated with

\footnotetext{
* Correspondence: inga.karu@regionaalhaigla.ee

${ }^{1}$ North Estonia Medical Centre, Clinic of Anaesthesiology, Tallinn, Estonia ${ }^{2}$ Department of Anaesthesiology and Intensive Care, University of Tartu, Puusepa 8, Tartu, Estonia

Full list of author information is available at the end of the article
}

morbidity and mortality, or excess systemic inflammatory response manifesting clinically as acute organ dysfunction. The concept of (ischemic) preconditioning-like cardioprotection induced by pre-treatment with hyperoxia has been reviewed recently [1]. Shortly, minimal concentration of oxygen in the inspired gas mixture evoking protective effect before subsequent ischemia in the rat heart is $80 \%$ and the most efficient $>95 \%$, with the duration of 30 minutes for mice and 60 minutes for rats [2-7]. Hyperoxia improves recovery of postischemic contractile function, reduces infarct size both in normal and atherosclerotic hearts of experimental animals, reduces incidence of ischemia-reperfusion induced 
arrhythmias and apoptotic cell death $[2,4,6,8-10]$. This preconditioning-like effect is at least partly explained by a low-grade oxidative stress due to hyperoxic exposure, which activates various protective mechanisms (antioxidant enzymes, etc.) in the myocardium. As a consequence 'readiness' to cope with the oxidative stress during reperfusion is achieved.

In the first clinical study investigating the cardioprotective potential of hyperoxia during cardiac surgery, we employed hyperoxic exposure for about 130 minutes immediately before cardiopulmonary bypass (CPB), but could not detect protective effect [11]. The absence of time period between hyperoxic exposure and cardioplegia, during which the protective mechanisms could be activated, could have been one possible explanation for this negative observation. On that background, we designed the protocol for the present study, which includes a normoxic window between hyperoxic exposure and beginning of the $\mathrm{CPB}$.

Cardiac surgery results in intense inflammatory response caused predominantly by surgical trauma, CPB and reperfusion injury. The effect of different cytokines in the heart is depending on different factors such as time of exposure and concentration [12,13]. Greater serum concentrations of tumour necrosis factor (TNF)- $\alpha$ and lower serum levels of interleukin (IL)-10 have been associated with increased prevalence of complications after $\mathrm{CPB}$ and may be indicative of a prominent proinflammatory state [14].

On that background, we aimed to evaluate cardioprotection conferred by adminisration of $>95 \%$ oxygen for 1 hour followed by normoxia up to initiation of CPB. Based on the previous clinical study and animal experiments we hypothesised that such pre-treatment provides enhanced myocardial protection described by decreased release of cardiac troponin $\mathrm{T}(\mathrm{cTn} \mathrm{T})$ in the $1^{\text {st }}$ postoperative morning (primary endpoint of the study) and reduces the release of inflammatory cytokines (secondary endpoints of the study). For complex evaluation of dynamics of the inflammatory response, a spectrum of pro- and anti-inflammatory cytokines was assessed.

\section{Methods}

\section{Patients}

The investigation conforms to the principles outlined in the Declaration of Helsinki. Ethical approval for this study was provided by the Ethics Review Committee on Human Research of the University of Tartu and a written informed consent was obtained from all patients. Forty adult patients scheduled for isolated primary elective CABG with at least 3 distal anastomoses were included and randomised into the control $(\mathrm{n}=20)$ and hyperoxia $(n=20)$ groups. The exclusion criteria were as follows: (1) preoperative infusion of vasoactive or inotropic medications, (2) diabetes mellitus treated either with insulin or oral medications, (3) hepatic, renal (serum creatinine $>150 \mu \mathrm{mol} / \mathrm{L}$ ) or pulmonary disease.

All medications, except salicylates were allowed until the day of surgery.

\section{Study protocol}

After induction of anesthesia and intubation of the trachea, patients were randomly allocated to receive either $40 \%$ or $>96 \%$ oxygen for 60 minutes (ventilator: Siemens $\mathrm{KIONi}$, Siemens-Elema AB, Sweden). Thereafter the mixture of oxygen and air was adjusted until the beginning of $\mathrm{CPB}$ to obtain arterial $\mathrm{pO}_{2}$ levels in the range of $100-150 \mathrm{mmHg}$. The fraction of oxygen in inspired gas mixture was continuously monitored by the gas analyser of the patient monitor Siemens SC9000XL (Dräger Medical System, Inc., Danvers, USA).

Arterial blood gases were analysed (Radiometer ABL 700 series, Radiometer Medical A/S, Copenhagen, Denmark) 10 and 60 minutes after randomisation and 10 and 60 minutes after the discontinuation of $\mathrm{CPB}$.

\section{Anesthesia and operative procedure}

Standardised intravenous anesthesia (midazolam, fentanyl, propofol, pancuronium) was used in all cases. Volatile anaesthetics were not used in order to avoid the confounding effect of a preconditioning-like state evoked by these agents. Nitroglycerine infusion (at least $1.0 \mathrm{mg} / \mathrm{h}$ ) was started after the induction of anesthesia. $\mathrm{CPB}$ was performed with a roller pump (Maquet Critica Care AB, Solna, Sweden) and a membrane oxygenator (Maquet Quatrox-I, Hirrlingen, Germany) under mild hypothermia (nasopharyngeal temperature $35-36^{\circ} \mathrm{C}$ ). Warm blood cardioplegia was given antegradely into the aortic root. Infusion was repeated at least once every 15-20 minutes. Distal anastomoses were performed under a single aortic cross-clamp while proximal anastomoses were performed under single side-clamp. After $\mathrm{CPB}$ the pulmonary capillary wedge pressure was kept above $8 \mathrm{mmHg}$ with the infusion of crystalloid and/or colloid solutions.

\section{Hemodynamic measurements}

Thermodilution pulmonary artery catheter was inserted after induction of anesthesia. Heart rate, mean arterial, central venous, pulmonary artery and pulmonary capillary wedge pressure and cardiac output were recorded at baseline (before sternotomy) and 15 minutes, 1, 2, 4, 6, 9, 12 and 18 hours after discontinuation of CPB. Cardiac index (CI), right and left ventricular stroke work indices and systemic and pulmonary vascular resistance indices were calculated using standard formulas. 


\section{Biochemical markers}

Blood was sampled from the radial artery cannula before induction of anesthesia and 1, 6, 18 and 40 hours after declamping the aorta. Blood was centrifuged immediately after sampling and serum stored at $-80^{\circ} \mathrm{C}$ until analyses.

cTn T was measured using STAT (Roche) electrochemiluminescence immunoassay on „ECLIA“; Analyzer: Cobas e 411.

Interleukin-1 $\alpha$, IL-2, IL-4, IL-6, IL-10, TNF- $\alpha$, and interferon gamma (IFN- $\gamma$ ) were analyzed with the Cytokine and Growth Factors High-sensitivity Array of the automated biochip immunoassay system, Evidence Investigator $^{\mathrm{Ts}}$ (Randox Laboratories Ltd., UK).

\section{Statistical analysis}

We chose a difference between means of cTn $\mathrm{T}$ values in the $1^{\text {st }}$ postoperative morning of $0.4 \mathrm{ng} / \mathrm{mL}$ as clinically important. For a significance level (alpha) of 0.05 (two-tailed) and $80 \%$ power we calculated that 20 patients in each group were needed.

Patient data were analysed using Student's $t$-test or Fisher's exact test, as appropriate.

Hemodynamic and normally distributed biochemical data were evaluated using analysis of variance (ANOVA) for repeated measures and represented as the mean (standard deviation). Part of the biochemical data (incl. the ratios) showed non-normal distribution and were analysed using non-parametric repeated measures (Friedman) ANOVA and the Mann-Whitney $U$-test; the results are represented as the median (interquartile range). In case of significant Friedman test results, Wilcoxon Matched Pairs test was used for post hoc analysis. All tests were two-sided and $\mathrm{p}<0.05$ was considered to be significant.

\section{Results}

Demographic data

Patients' characteristics are given in Table 1. There were no inter-group differences regarding age of the patients, ischemic time and number of grafted vessels. Significantly higher number of patients in the control group received calcium channel blocking drugs, otherwise the preoperative usage of medications did not differ between groups. Inotropic support (dobutamine as the agent of first choice) was administered in case of cardiac index $<2.5 \mathrm{~L} \mathrm{~min} / \mathrm{m}^{2}$, systolic blood pressure $<90 \mathrm{mmHg}$ and pulmonary capillary wedge pressure $>8 \mathrm{mmHg}$.

One patient was excluded due to missing hemodynamic measurements and blood sample at one time point, so results of 19 patients in the control group were analysed.

All patients experienced an uneventful recovery; i.e. there was no mortality or serious morbidity in this patient population.

\section{Myocardial necrosis}

Myocardial necrosis was not detectable preoperatively. In the $1^{\text {st }}$ postoperative morning the concentrations of cTn $\mathrm{T}$ did not differ between groups (0.44 (0.26-0.55) $\mathrm{ng} / \mathrm{mL}$ in the control and $0.45(0.37-0.71) \mathrm{ng} / \mathrm{mL}$ in the hyperoxia group) (Figure 1). No significant differences were found between groups.

Table 1 Characteristics of patients, oxygenation and surgical data

\begin{tabular}{|c|c|c|c|}
\hline \multirow[t]{2}{*}{ Variable } & \multirow{2}{*}{$\frac{\text { Controls }}{(n=19)}$} & \multirow{2}{*}{$\frac{\text { Hyperoxia pretreated }}{(n=20)}$} & \multirow[t]{2}{*}{ p-value } \\
\hline & & & \\
\hline Age (years) & $65(8)$ & $66(11)$ & 0.89 \\
\hline Gender (male/female) & $15 / 5$ & $14 / 5$ & 0.67 \\
\hline \multicolumn{4}{|l|}{ Preoperative medications } \\
\hline Ca-channel blockers, n (\%) & $6(31.5)$ & $1(5)$ & 0.01 \\
\hline Nitrates, n (\%) & $12(63)$ & $8(40)$ & 0.13 \\
\hline$\beta$-blockers, n (\%) & $17(89)$ & $14(70)$ & 0.13 \\
\hline ACE-inhibitors, n (\%) & $14(74)$ & $10(50)$ & 0.11 \\
\hline Statins, n (\%) & $15(79)$ & $11(55)$ & 0.27 \\
\hline Preoperative ejection fraction (\%) & $58(11)$ & $53(11)$ & 0.16 \\
\hline $\mathrm{p}_{\mathrm{a}} \mathrm{O}_{2} 10$ min after intubation $(\mathrm{mmHg})$ & $130(49)$ & $402(68)$ & $<0.001$ \\
\hline $\mathrm{p}_{\mathrm{a}} \mathrm{O}_{2} 60$ min after intubation $(\mathrm{mmHg})$ & $108(27)$ & $369(75)$ & $<0.001$ \\
\hline Cross-clamping time (min) & $47(33)$ & $46(30)$ & 0.89 \\
\hline Duration of cardiopulmonary bypass (min) & $68(36)$ & $63(27)$ & 0.66 \\
\hline Number of vessels bypassed & $3.3(0.8)$ & $3.5(0.8)$ & 0.50 \\
\hline Need for inotropic support, n (\%) & $7(37)$ & $6(30)$ & 0.80 \\
\hline
\end{tabular}

Values are provided as incidence (\%) or mean (SD). 


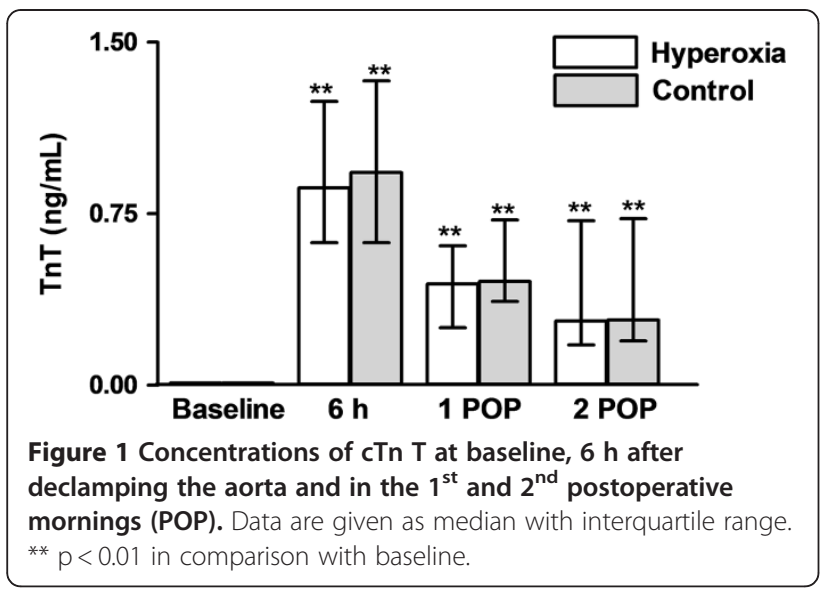

\section{Inflammation}

\section{Proinflammatory markers}

Values of interleukin-1 $\alpha(0.16(0.15) \mathrm{pg} / \mathrm{mL}$ in the control and $0.13(0.08) \mathrm{pg} / \mathrm{mL}$ in the hyperoxia group) and interleukin-1 $\beta(0.83(0.76) \mathrm{pg} / \mathrm{mL}$, and $0.94(0.71) \mathrm{pg} /$ $\mathrm{mL}$, respectively) did neither differ preoperatively between groups nor change significantly during the study period. The values of interleukin-2 did not differ between groups $((1.87(0.57) \mathrm{pg} / \mathrm{mL}$ in controls vs 1.90 (1.02) $\mathrm{pg} / \mathrm{mL}$ in hyperoxia pre-treated patients) perioperatively (data not shown).

Concentrations of IL-6,8, TNF- $\alpha$ and IFN- $\gamma$ increased after cardiopulmonary bypass, but this was not affected by pre-treatment by hyperoxia (Figure 2).

\section{Anti-inflammatory markers}

Iinterleukin-4 did not show any systemic changes over the time (Figure 3, panel A).

Interleukin-10, in contrast, peaked 60 minutes after declamping the aorta and declined already by the $6^{\text {th }}$ post-declamping hour in both groups. Still, when compared to baseline, the values remained significantly elevated for 2 postoperative days (Figure 3, panel B).

\section{Ratios of pro- and anti-inflammatory markers}

Highest IL-10 to IL-6 ratio was detected at $60^{\text {th }}$ minute after declamping ( 0.73 in the controls and 1.47 in the hyperoxia group, $\mathrm{p}=0.03)$. Thereafter the values in both groups were decreased to even below the baseline (Figure 4, panel A). IL-10 to TNF- $\alpha$ ratio behaved in a similar manner, showing maximal values and significant difference between groups at $60^{\text {th }}$ minute after declamping (2.91 in the controls and 8.81 in the hyperoxia group, $\mathrm{p}=0.015$ ) and decreasing thereafter (Figure 4, panel B). Higher IL-10 to IL-6 ratio in the hyperoxia group was mainly caused by higher IL-10 levels.

\section{Hemodynamic measurements}

Preoperative mean CI was $2.2(0.4)$ in the control and $2.1(0.7) \mathrm{L} \mathrm{min} / \mathrm{m}^{2}$ in the hyperoxia group. After $\mathrm{CPB}$ the $\mathrm{CI}$, as well as left and right ventricular stroke work indices were not significantly different from with the baseline and no intergroup differences were found.
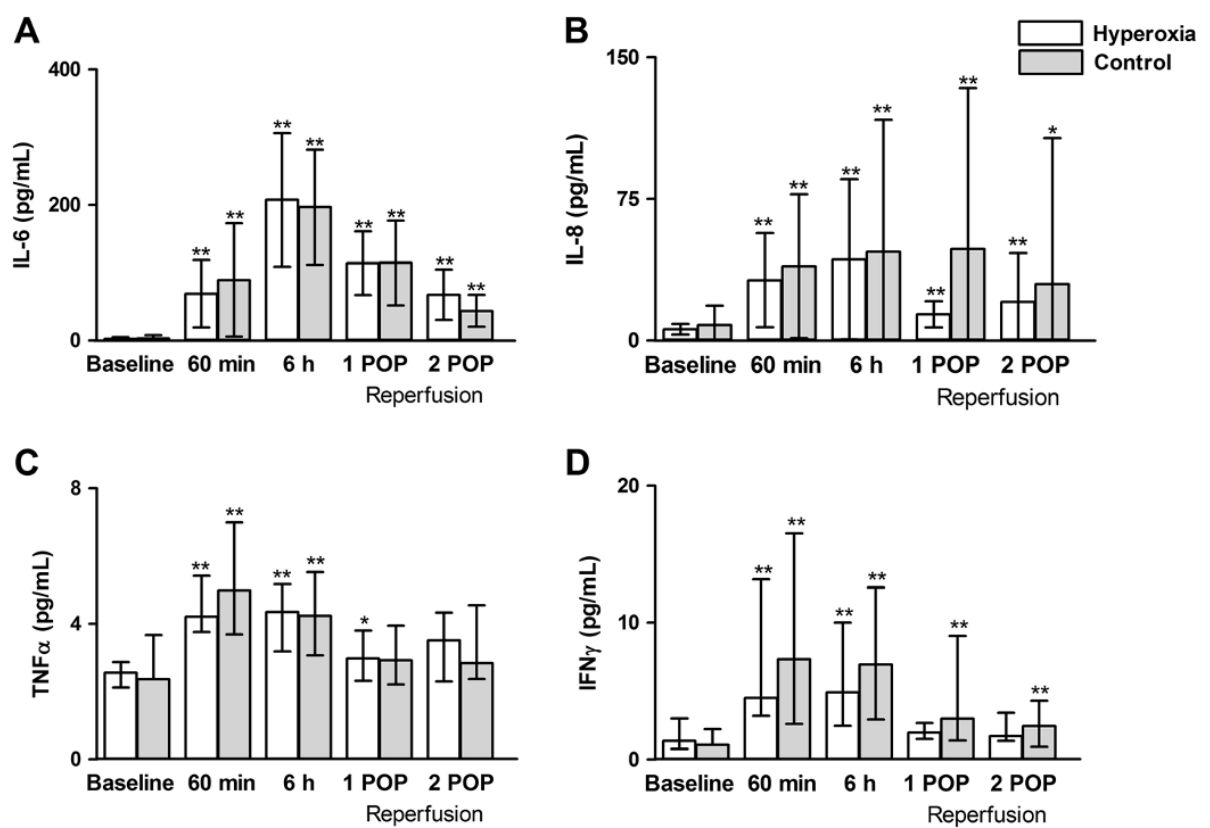

Figure 2 Concentrations of proinflammatory cytokines (IL-6 - panel A, IL-8 - panel B, TNFa - panel B, IFN - panel D) at baseline, $6 \mathrm{~h}$ after declamping the aorta and in the $1^{\text {st }}$ and $2^{\text {nd }}$ postoperative mornings (POP). Data are given as mean (SD) - panels $\mathbf{A}, \mathbf{B}$ and as median (interquartile range) - panels $\mathbf{C}, \mathbf{D}$. ${ }^{* *} p<0.01$ in comparison with baseline, ${ }^{*} p<0.05$ in comparison with baseline. 

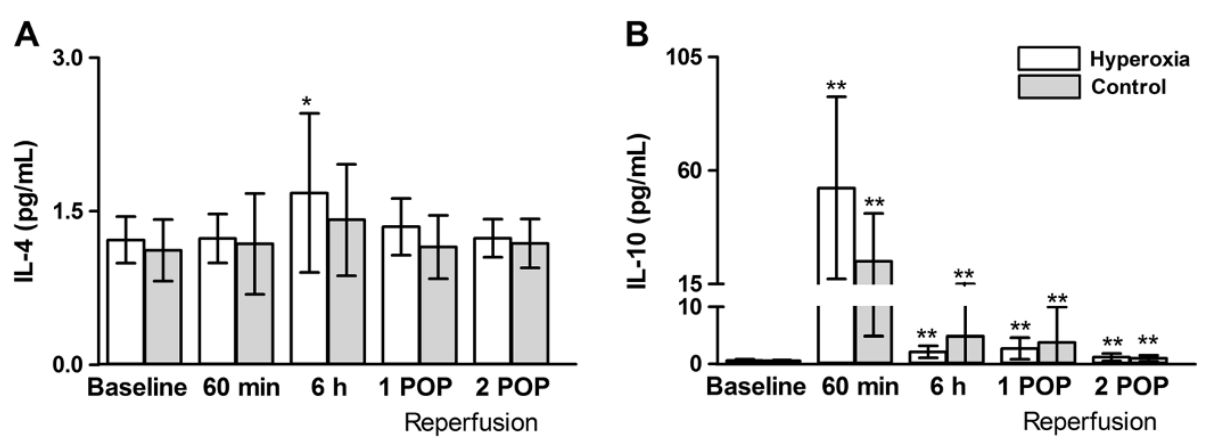

Figure 3 Concentrations of anti-inflammatory cytokines (IL-4 - panel A, IL-10 - panel B) at baseline, $6 \mathrm{~h}$ after declamping the aorta and in the $1^{\text {st }}$ and $2^{\text {nd }}$ postoperative mornings (POP). Data are given as mean (SD). ${ }^{* *} p<0.01$ in comparison with baseline, ${ }^{*} p<0.05$ in comparison with baseline.

\section{Discussion}

Present study demonstrates that pre-treatment with 60 minutes of hyperoxia followed by 33 (18-59) min normoxia before $\mathrm{CPB}$ does not afford protection against myocardial injury (cTn T release or myocardial function) associated with coronary artery bypass grafting. This is in accordance with our previous study where a different protocol of hyperoxic pretreatment was implemented [11]. We established that surgery was associated with a well-defined release of systemic inflammatory mediators, and in patients ventilated with $>95 \%$ oxygen before $\mathrm{CPB}$ the ratios of IL-10/IL- 6 and IL-10/TNF- $\alpha$ were drifted towards anti-inflammatory. It could be a reflection of changes in the inflammatory response network/profile due to pre-treatment with hyperoxia.

By now we have tested two different times of hyperoxic exposure in clinical studies - 60 minutes followed by normoxia in the present and about 130 minutes immediately before CPB in a previous study [11]. We did not find clinically relevant reduction of myocardial injury (release of cardiac troponin), although this manipulation resulted in some changes in the inflammatory profile. There can be several reasons for that. First, it could be speculated that in case of modern myocardial protection techniques only minimal myocardial injury is caused by cardioplegic cardiac arrest and there is no need for activation of intrinsic protective mechanisms. The situation is different in animal experiments where myocardial protective techniques are not used and injury is therefore well described. Although we included patients with at least 3-vessel CABG surgery, the aortic cross-clamping time of about 46 minutes could have been too short. Also, in power analysis we expected reduction of cTn $\mathrm{T}$ by 0.4 $\mathrm{ng} / \mathrm{mLin}$, which probably overestimates cardioprotective effect of whatever hypothetical intervention in these particular patients. To detect a difference of $0.1 \mathrm{ng} / \mathrm{mL}$ (the clinical relevance of which remains questionable), a study with several hundreds of patients needs to be conducted. Secondly, in difference from mice and rats, hyperoxic exposure of one or two hours in humans might be too weak stimulus to activate protective pathways. There is no direct evidence to support or oppose this idea. Some speculations might be drawn from the inter-species comparisons of myocardial injury in relation to duration of ischemia. For example, in rodent models of myocardial infarction, 30-40 minutes of either regional or global myocardial ischemia is sufficient to induce an infarct size of $50 \%$ of the area at risk. In the porcine heart,
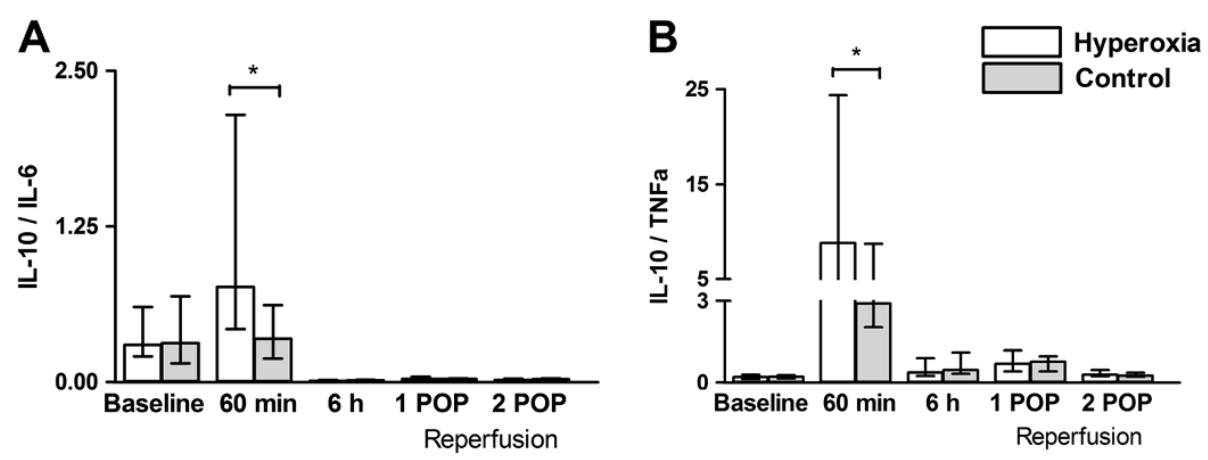

Figure 4 Ratio of IL-10/IL-6 (panel A) and IL-10/TNFa (panel B) at baseline, $6 \mathrm{~h}$ after declamping the aorta and in the $1^{\text {st }}$ and $2^{\text {nd }}$ postoperative mornings (POP). Data are given as median with interquartile range. ${ }^{*} p<0.05$ in comparison with baseline. 
significantly longer duration (60-90 minutes) of myocardial ischemia is required to achieve equivalent levels of infarction. Human myocardial infarcts generally require 90 minutes to become established [15]. Whether these data can be extrapolated to the exposure time of hyperoxia that is needed to activate endogenous cardioprotective mechanisms, is not clear. In addition, it has been shown recently that in comparison with human broncho-alveolar fluid proteome, oxidative stress response was selectively enriched only in mice [16]. Regarding the response to pretreatment by hyperoxia, interspecies differences in evoking protective effect have been described even in the hearts of mice and rats ${ }^{[5]}$. Thirdly, there is a possibility that the phenomenon of hyperoxia induced myocardial protection does not exist in humans at all. In vitro studies, however, suggest that human myocardium can be preconditioned [17]. Several in vivo surrogate models of ischaemic preconditioning have showed protective effect preinfarction angina, repeated balloon inflations, intermittent aortic cross-clamping. Similar to these, hyperoxia has been shown to be a preconditioning evoking stimulus both in rodents and in human in vitro studies [2-10].

One factor that could also have an impact on the results is the preoperative usage of statins and angiotensin converting enzyme (ACE) inhibitors. Statins have shown to evoke cardioprotective effects both in animal models of ischemia-reperfusion injury and in clinical studies (reviewed by Ludman et al. [18]), and have the ability to reduce IL- 6 and IL- 8 after coronary surgery [19]. ACE inhibitor treatment is associated with a reduction of IL-6 response to CABG [20] and confers added myocardial protection during surgical revascularisation [21].

Observed activation of inflammation in response to CPB is well in accordance with previous studies. TNF- $\alpha$ is a proinflammatory cytokine, which plays a central role in initiating and sustaining inflammation [22]. It enhances oxidative stress in adult cardiac myocytes both by increasing reactive oxygen species generation as well as by decreasing antioxidants. Overexpression of TNF- $\alpha$ leads to cell injury due to excessive oxidative stress [23]. IL-10 demonstrates potent anti-inflammatory properties through inhibiting the production of TNF- $\alpha$ and other proinflammatory cytokines [24]. It has revealed to possess antioxidant like properties in situations where oxidative stress is increased [25].

IL-10 has been shown to inhibit the production of reactive oxygen species in isolated macrophages [25] and has been suggested to modulate TNF- $\alpha$ mediated, oxidative-stress- induced acute lung injury [14,26,27]. After elective cardiac surgery the ratio of IL-10/TNF- $\alpha$ messenger RNA has shown to be an independent predictor of outcome, and thus IL-10 may have a protective role after cardiac surgery [28]. Hence, an appropriate balance between IL-10 and TNF- $\alpha$ may be of crucial importance. In the present study we observed a temporary increase of IL-10/IL- 6 and IL-10/TNF- $\alpha$ ratios in the hyperoxia pre-treated patients, which suggests a change of the inflammatory profile towards anti-inflammatory. This can be a circumambage that hyperoxia may reduce inflammatory response immediately after CPB. Changes in immune system occur in 2 phases after cardiac surgery [29]. The $1^{\text {st }}$ phase represents the pro- and antiinflammatory reaction returning to normal by the $3^{\text {rd }}$ postoperative day. This is the cause of systemic inflammatory response with well known clinical manifestations as acute organ dysfunctions and failures. The $2^{\text {nd }}$ phase emerges on postoperative day 5 and is characterised mainly by anti-inflammatory type of reaction. The synthesis of IFN- $\gamma$ is significantly reduced after cardiac surgery and postoperative immunosuppression phenomenon in cardiac surgical patients has been well described [30].

\section{Conclusion}

Pre-treatment by hyperoxia for 60 minutes followed by normoxia did not reduce postoperative leak of cTn $\mathrm{T}$ in patients undergoing coronary artery bypass surgery, but drifted ratios of IL-10/IL-6 and IL-10/TNF $\alpha$ towards anti-inflammatory.

\section{Competing interests}

The authors declare that they have no competing interests.

\section{Authors' contributions}

JS was involved in designing the study and revised the manuscript critically. PT and AR collected data and helped with revision of the manuscript. IK collected and analysed data and wrote the paper. KZ was responsible for the biochemical analysis. MZ helped to interpret the data and revised the manuscript critically. All authors read and approved the final manuscript.

\section{Acknowledgements}

This work was supported by the Estonian Science Foundation grants No. 8227 and 7080, by the targeted financing (No. 0180105s08) and by the European Union through the European Regional Development Fund. Help of statistician Ülle Kirsimägi, MSc (Department of Surgery, University of Tartu, Estonia) is greatly acknowledged.

\section{Author details}

${ }^{1}$ North Estonia Medical Centre, Clinic of Anaesthesiology, Tallinn, Estonia. ${ }^{2}$ Department of Anaesthesiology and Intensive Care, University of Tartu, Puusepa 8, Tartu, Estonia. ${ }^{3}$ Department of Cardiology, University of Tartu, Tartu, Estonia. ${ }^{4}$ Tartu University Hospital, Tartu, Estonia. ${ }^{5}$ Institute of Biochemistry, Centre of Excellence for Translational Medicine, University of Tartu, Tartu, Estonia.

Received: 18 April 2012 Accepted: 11 September 2012

Published: 14 September 2012

\section{References}

1. Karu I, Tähepõld P, Ruusalepp A, Starkopf J: Pretreatment by hyperoxia-a tool to reduce ischaemia-reperfusion injury in the myocardium. Curr Clin Pharmacol 2010, 5:125-132.

2. Tähepõld P, Valen G, Starkopf J, Kairane C, Zilmer M, Vaage J: Pretreating rats with hyperoxia attenuates ischemia-reperfusion injury of the heart. Life Sci 2001, 68:1629-1640.

3. Colantuono G, Tiravanti EA, Di Venosa N, Cazzato A, Rastaldo R, Cagiano R, D'Agostino D, Federici A, Fiore T: Hyperoxia confers myocardial protection 
in mechanically ventilated rats through the generation of free radicals and opening of mitochondrial ATP-sensitive potassium channels. Clin Exp Pharmacol Physiol 2008, 35:64-71

4. Li G, Tokuno S, Tähepõld P, Vaage J, Löwbeer C, Valen G: Preconditioning protects the severely atherosclerotic mouse heart. Ann Thorac Surg 2001, 71:1296-1304

5. Tähepõld P, Ruusalepp A, Li G, Vaage J, Starkopf J, Valen G: Cardioprotection by breathing hyperoxic gas - relation to oxygen concentration and exposure time in rats and mice. Eur J Cardiothor Surg 2002, 21:987-994.

6. Esmaili Dehaj M, Baharvand B, Rasoulian B, Foadaddini M, Asgari A Noroozzadeh A, Poorkhalili K, Wahhab Aghai H, Khoshbaten A: Delayed protective effects of hyperoxia against cardiac arrhythmias and infarction in anesthetized rats. J Surg Res 2009, 151:55-61.

7. Kaljusto ML, Stensløkken KO, Mori T, Panchenko A, Frantzen ML, Valen G, Vaage J: Preconditioning effects of steroids and hyperoxia on cardiac ischemia-reperfusion injury and vascular reactivity. Eur J Cardiothorac Surg 2008, 33:355-363.

8. Tähepõld P, Elfström P, Eha I, Kals J, Taal G, Talonpoika A, Valen G, Vaage J, Starkopf J: Exposure of rats to hyperoxia enhances relaxation of isolated aortic rings and reduces infarct size of isolated hearts. Acta Physiol Scand 2002, 175:271-277.

9. Pourkhalili K, Hajizadeh S, Tiraihi T, Akbari Z, Esmailidehaj M, Bigdeli MR, Khoshbaten A: Ischemia and reperfusion-induced arrhythmias: role of hyperoxic preconditioning. J Cardiovasc Med (Hagerstown) 2009, 10:635-642.

10. Foadoddini M, Esmailidehaj M, Mehrani H, Sadraei SH, Golmanesh L, Wahhabaghai H, Valen G, Khoshbaten A: Pretreatment with hyperoxia reduces in vivo infarct size and cell death by apoptosis with an early and delayed phase of protection. Eur J Cardiothorac Surg 2011, 39:233-240

11. Karu I, Loit R, Zilmer K, Kairane C, Paapstel A, Zilmer M, Starkopf J: Pretreatment with hyperoxia before coronary artery bypass grafting effects on myocardial injury and inflammatory response. Acta Anaesthesiol Scand 2007, 51:1305-1313.

12. Wilson EM, Diwan A, Spinale FG, Mann DL: Duality of innate stress responses in cardiac injury, repair, and remodeling. $\mathrm{J} \mathrm{Mol} \mathrm{Cell} \mathrm{Cardiol}$ 2004, 37:801-811.

13. Linde A, Mosier D, Blecha F, Melgarejo T: Innate immunity and inflammation-New frontiers in comparative cardiovascular pathology. Cardiovasc Res 2007, 73:26-36.

14. Wan S, LeClerc JL, Schmartz D, Barvais L, Huynh CH, Devière J, DeSmet JM, Vincent $J$ : Hepatic release of interleukin-10 during cardiopulmonary bypass in steroid-pretreated patients. Am Heart J 1997, 133:335-339.

15. Ludman AJ, Yellon DM, Hausenloy DJ: Cardiac preconditioning for ischaemia: lost in translation. Dis Model Mech 2010, 3:35-38.

16. Gharib SA, Nguyen E, Altemeier WA, Shaffer SA, Doneanu CE, Goodlett DR, Schnapp LM: Of mice and men: comparative proteomics of bronchoalveolar fluid. Eur Respir J 2010, 35:1388-1395.

17. Walker DM, Walker JM, Pugsley WB, Pattison CW, Yellon DM: Preconditioning in isolated superfused human muscle. J Mol Cell Cardiol 1995, 27:1349-1357.

18. Ludman A, Venugopal V, Derek M, Yellon D, Derek J, Hausenloy D: Statins and cardioprotection - More than just lipid lowering? Pharmacol Ther 2009, 122:30-43.

19. Chello M, Anselmi A, Spadaccio C, Patti G, Goffredo C, Di Sciascio G, Covino E: Simvastatin increases neutrophil apoptosis and reduces inflammatory reaction after coronary surgery. Ann Thorac Surg 2007, 83:1374-1380.

20. Brull DJ, Sanders J, Rumley A, Lowe GD, Humphries SE, Montgomery HE: Impact of angiotensin converting enzyme inhibition on post-coronary artery bypass interleukin 6 release. Heart 2002, 8:7252-255.

21. Benedetto U, Melina G, Capuano F, Comito C, Bianchini R, Simon C, Refice S, Angeloni E, Sinatra R: Preoperative angiotensin-converting enzyme inhibitors protect myocardium from ischemia during coronary artery bypass graft surgery. Cardiovasc Med (Hagerstown) 2008, 9:1098-1103.

22. Ksontini R, Mackay SL, Moldawer LL: Revisiting the role of tumor necrosis factor alpha and the response to surgical injury and inflammation. Arch Surg 1998, 133:558-567.

23. Kaur K, Sharma AK, Dhingra S, Singal PK: Interplay of TNF-a and IL-10 in regulating oxidative stress in isolated adult cardiac myocytes. $\mathrm{J} \mathrm{Mol} \mathrm{Cell}$ Cardiol 2006, 41:1023-1030.
24. Bolger AP, Sharma R, von Haehling S, Doehner W, Oliver B, Rauchhaus M, Coats AJ, Adcock IM, Anker SD: Effect of interleukin-10 on the production of tumor necrosis factor-alpha by peripheral blood mononuclear cells from patients with chronic heart failure. Am J Card 2002, 90:384-389.

25. Dokka S, Shi X, Leonard S, Wang L, Castranova V, Rojanasakul Y: Interleukin10-mediated inhibition of free radical generation in macrophages. Am J Physiol Lung Cell Mol Physiol 2001, 280:L1196-L1202.

26. Mulligan MS, Jones ML, Vaporciyan AA, Howard MC, Ward PA: Protective effects of L-4 and IL-10 against immune complex-induced lung injury. J Immunol 1993, 151:5666-5674.

27. Shanley TP, Schmal H, Friedl HP, Jones ML, Ward PA: Regulatory effects of intrinsic IL-10 in IgG immune complex-induced lung injury. J Immunol 1995, 154:3454-3460.

28. Duggan E, Caraher E, Gately K, O'Dwyer M, McGovern E, Kelleher D, McManus R, Ryan T: Tumor necrosis factor-alpha and interleukin-10 gene expression in peripheral blood mononuclear cells after cardiac surgery. Crit Care Med 2006, 34:2134-2139.

29. Franke A, Lante W, Fackeldey V, Becker HP, Thode C, Kuhlmann WD, Markewitz A: Proinflammatory and antiinflammatory cytokines after cardiac operation: different cellular sources at different times. Ann Thorac surg 2002, 74:363-370.

30. Franke A, Lante W, Kurig E, Zöller LG, Weinhold C, Markewitz A: Is interferon gamma suppression after cardiac surgery caused by a decreased interleukin-12 synthesis? Ann Thorac Surg 2006, 82:103-109.

doi:10.1186/1477-5751-11-14

Cite this article as: Karu et al:: Effects of 60 minutes of hyperoxia followed by normoxia before coronary artery bypass grafting on the inflammatory response profile and myocardial injury. Journal of Negative Results in BioMedicine 2012 11:14.

\section{Submit your next manuscript to BioMed Central and take full advantage of:}

- Convenient online submission

- Thorough peer review

- No space constraints or color figure charges

- Immediate publication on acceptance

- Inclusion in PubMed, CAS, Scopus and Google Scholar

- Research which is freely available for redistribution 